\title{
O PROFETA RADICAL ${ }^{1}$
}

\author{
Mark Bauerlein ${ }^{2}$
}

Em 1987, não muito depois que David Horowitz completou sua transição de um radical dos anos de 1960 para um conservador nos anos 1980, ele recebeu uma carta de uma ex-camarada. Eles tinham acabado de ter uma discussão política por telefone e ela queria encerrar a conversa com um sumário de sua renúncia da esquerda mais combativa. Ambos foram filhos de pais socialistas, estudaram na Escola Progressista de Sunnyside e eram filhos de membros do Partido Comunista num enclave no Queens, Nova Iorque. Agora, aquele companheiro de barricadas tinha decidido apoiar "as vilanias de Ronald Reagan". Por quê?

Ela escreveu um parágrafo esclarecendo suas próprias posições em relação ao stalinismo e ao socialismo: "Há classes e os ricos não estão do mesmo lado do resto de nós. Eles são exploradores". Quando ela se referiu a Horowitz, no entanto, tem-se uma explicação totalmente diferente. Horowitz ainda não tinha escrito Radical Son: $A$ Generational Odyssey (1997), uma prestação de contas poderosa consigo mesmo diante da trajetória que percorreu do movimento contra as guerras e os Panteras Negras até o Partido Republicano - mas ela já tinha compreendido a causa:

\section{Horowitz,}

Não posso deixar de pensar que suas atuais visões são de ordem psicológica e não intelectuais (...) você está operando a partir de uma posição emocional na qual suprime o pensamento racional. E no mais (...) você aparenta não ter a capacidade de tolerar ambiguidade.

Note a mudança de diagnóstico. Horowitz mudou suas visões políticas, mas não porque notou como a esquerda abandonou os sul-vietnamitas depois que o Exército americano saiu; ou porque a esquerda, depois dos anos 1970, deu uma guinada apocalíptica (com grupos como The Weathermen, etc.), o que o assustava; nem mesmo com a postura de "culpe os EUA primeiro" acerca de lugares como Camboja, Cuba e União Soviética em 1985 (essas foram as razões que Horowitz havia alegado naquele ano em artigo escrito com Peter Collier no The Washington Post, intitulado "Adeus a tudo aquilo").

\footnotetext{
1 No original, "Radical Prophet", publicado em 1o de agosto de 2018. Artigo traduzido e adaptado por Ariel Finguerut, membro do Conselho Editorial da Revista Malala, com autorização do autor. Artigo originalmente publicado pela Claremont Review of Books, v. XVIII, n. 3, Summer 2018. Disponível em: https://www. claremont.org/crb/article/radical-prophet/.

2 Mark Bauerlein é professor de inglês na Emory University, localizada na região metropolitana de Atlanta, Geórgia, EUA.
} 


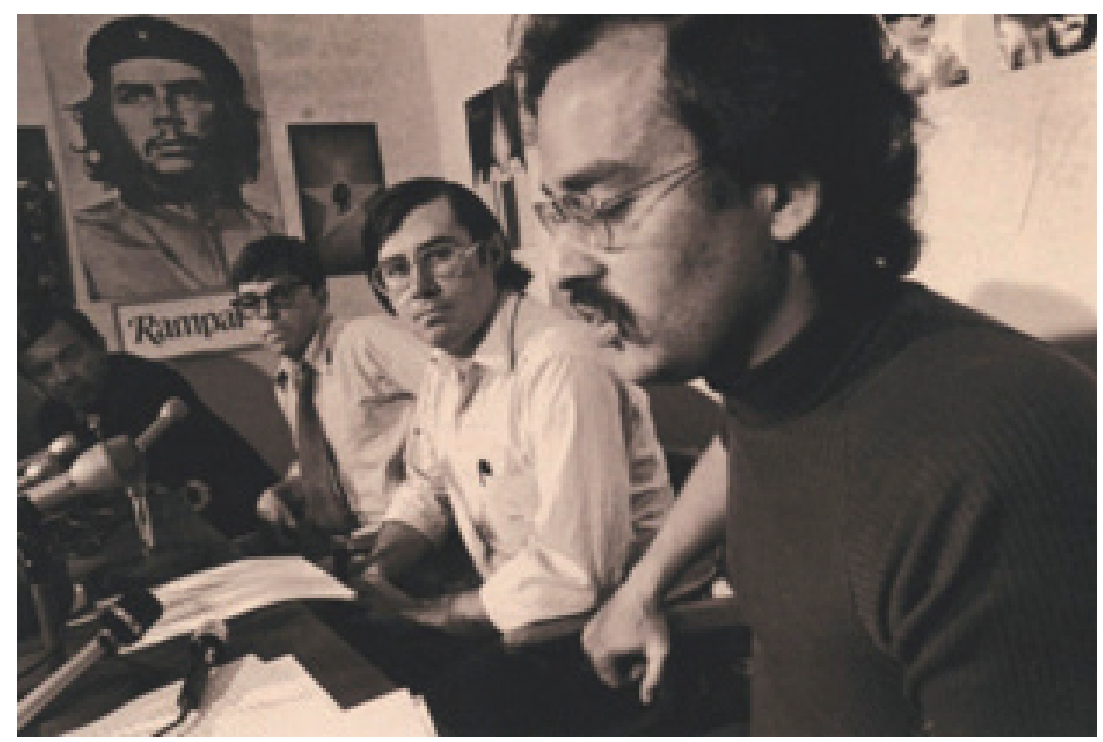

Quando David Horowitz (o terceiro da esquerda para a direita) ainda era de esquerda, na sede da revista Rampage, em Berkeley, $1967^{3}$

Não, para a velha amiga de Horowitz, as causas só podem ser patológicas. Um defeito psíquico - essa é a raiz de sua apostasia. Ele está muito chateado; ele não suporta ambiguidade; ele é irracional. Socialistas sabem que o mundo é complicado, mas a mente socialista tornou-se neuroticamente simplista. É por isso que ele mudou de lado.

A alegação machucou, Horowitz admite. Mas significou algo importante sobre seus então companheiros, a ponto de ele republicar a carta na revista Ruling Ideas, nono o último volume de sua prestação de contas pessoal com a história dos movimentos radicais de esquerda dos anos de 1950 em diante. 0 nome do projeto como um todo ficou The Black Book of the American Left (O livro negro da esquerda americana, em português). 0 título ecoa o clássico organizado por Stéphane Courtois, O livro negro do comunismo, publicado na França em 1997, ${ }^{4}$ no qual, com pesquisa em documentos recentemente abertos da então Cortina de Ferro, estima que o comunismo matou mais de 90 milhões de pessoas. A obra francesa foi um sucesso editorial e decisiva para muitos abandonarem as ideologias de esquerda. Uma vez perguntei ao historiador marxista Eugene Genovese como ele pôde permanecer um comunista nos anos de 1960 e 1970 uma vez que não faltavam evidências mostrando e confirmando os tribunais de execução, os gulags (centros de concentração e de trabalho forçado da URSS). E ele respondeu: “Nós acreditávamos que, se o paraíso dos trabalhadores iria acontecer, uma geração teria que ser mesmo sacrificada". O livro negro do comunismo mostrou que as utopias subestimavam o custo (em termos de mortos) sem entregar o benefício prometido.

\footnotetext{
${ }^{3}$ Fonte: acervo do jornal Denver Westword (https://www.westword.com/news/david-horowitz-hasturned-taunting-muslims-into-a-spectator-sport-5118887). Acessado em 11/11/2018.

4 Nota do tradutor: no Brasil, publicado pela editora Record, RJ, 1999.
} 


\section{retrato intelectual}

\section{A realização de uma vida}

The Black Book of the American Left tinha a mesma intenção e se servia ao mesmo propósito: contar a verdade sobre o movimento político que ainda inspira pessoas e de tempos em tempos reaparece (como a apresentação ao estilo Panteras Negras da cantora Beyoncé no Super Bowl, ${ }^{5}$ com camisetas de Che Guevara). A coleção inteira está praticamente publicada [nos EUA]. Trata-se da realização de uma vida de um "guerreiro cultural" - ou, talvez, a metade da realização de uma vida, pois nessa obra apenas os trabalhos de Horowitz já conservador estão incluídos, não os livros e ensaios escritos pelo Horowitz ainda socialista nos anos 1960, nem seu trabalho editorial na revista Ramparts, publicação de liderança da Nova Esquerda até seu fechamento, em 1975 (ele se lembra da capa de uma revista que circulou durante a campanha presidencial de 1972 e que tinha uma fotografia das atrocidades em My Lai, seguida por um pôster de campanha em que se lia: "Reeleja o presidente"). John Fonte, que revisou os dois primeiros volumes no número de julho de 2014 da Claremont Review of Books, enfatiza como Horowitz se propõe a um rigor que deixa de lado uma leitura mais sentimental da esquerda que aparece nos livros didáticos do ensino médio e na mídia popular. Particularmente, Horowitz se opõe com veemência à associação ou transmutação comum na mídia do esquerdismo como meramente liberal. Desde então, sete outros volumes foram organizados por temas e publicados: $^{6}$ The Great Betrayal; Culture Wars; Progressive Racism - em cada um desses volumes o autor expõe os objetivos e métodos das pessoas que Fante, em sua resenha, classifica como "as fraudes da esquerda e daqueles que fazem pose de autoridade suprema".

O objetivo é parar de romantizar a esquerda, ter um olhar não romântico semidealismo e sem os típicos atenuantes que são aplicados para o que, no fundo, é subterfúgio para objetivos radicais, objetivos estes que o próprio Horowitz se coloca como uma testemunha. Ele estava lá, ele foi um deles, foi membro do círculo Huey Newton, um organizador comunitário dos guetos de Oakland que pregava por apoio da esquerda à eleição de Ronald Reagan ao governo da Califórnia. A ideia aqui era simples: ao supostamente eleger um genuíno fascista, isso ajudaria a realização da revolução. Horowitz argumenta contra a esquerda radical nos termos desse testemunho, com base no que ele viu e ouviu, especialmente fora dos espaços públicos, quando seus então companheiros falavam de modo mais honesto sobre seus propósitos.

O primeiro volume, intitulado "Minha vida e os tempos", ilustrou como a crítica autobiográfica funciona. Nós temos, por exemplo, o conto de Ann Colloms. Ela era a mãe de um amigo de infância. Por fora parecia uma progressista moderada, mas se revelava, por dentro, uma partidária ardente do comunismo.

Muitos anos depois, no final dos anos de 1970, ela se dirigiu a Horowitz para revelar

\footnotetext{
${ }^{5}$ Nota do tradutor: cf. trecho em questão em https://www.youtube.com/watch?v=uqGwekWZeRI. Acessado em 11/11/2018 (nota do tradutor)

${ }^{6}$ Nota do tradutor: cf. todos os volumes em http://www.blackbookoftheamericanleft.com/. Acessado em $11 / 11 / 2018$.
} 


\section{retrato intelectual}

algo que tinha acontecido antes da guerra. Em 1940, ela foi selecionada pelo partido para uma missão especial: iria carregar um envelope fechado até o México, onde encontraria um contato não identificado em um lugar predeterminado, lhe entregaria o envelope e retornaria para casa. E isso seria toda a informação que ela teria. Horowitz se lembrava dela como uma pessoa modesta, uma mulher de classe média como muitas outras, com uma bebê para alimentar e uma casa para cuidar. Mas esse dever dado pelo partido transcendia isso tudo. "Foi o partido que pediu, mas foi a história que me chamou", Horowitz explica, "e ela respondeu a esse chamado". Apenas depois, quando ela soube que Leon Trotsky tinha sido assassinado na Cidade do México, é que seu papel como um elo em alguma forma de cadeia de comunicação letal se tornou mais claro.

Ela já era uma senhora quando visitou Horowitz, mas tal episódio ainda a perturba. Ela tinha que confessar e, ao escolhê-lo, nós presumimos, foi porque já sabia que ele tinha se afastado da esquerda. Ele a apresenta como uma lição sobre o que o partido exigia: você deve se despersonalizar. Socialistas anti-stalinistas como o jovem Horowitz idolatravam Trotsky; ele, entretanto, a tratou com simpatia. Não foi preciso uma análise ideológica para completar a história; o preço emocional cobrado pela ideologia foi alto.

\section{Crentes de verdade}

O número mais recente da Ruling Ideas fornece mais reminiscências. É possível ler sobre seu mentor, Isaac Deutscher, o historiador do comunismo que exaltava Trotsky como um herói romântico; Jessica Mitford, a renomada reformista que procurou um jornal progressista que aceitasse o relato crítico de Horowitz e Collier sobre os Panteras Negras para censurá-lo antes da publicação; Ellen Spares, outra amiga de infância, filiada ao partido e instrutora no Queens College, onde acabou sendo morta depois de ter sido estuprada por um estudante que ela recusava reconhecer como perigoso por supostamente ser de "classe oprimida"; e Christopher Hitchens, que não se encaixa na categoria de "ingênuo" nem na de radical não arrependido (mais sobre isso abaixo).

O caso do pai de Horowitz é o mais triste. Um evento decisivo em sua vida aconteceu em 1953, alguns anos depois de o estado de Nova Iorque proibir comunistas de trabalhar como professores em escolas públicas. Por 29 anos o velho Horowitz foi professor na Seward Park High School, no bairro conhecido como Lower East Side. Ele tinha uma família para sustentar e precisava do trabalho, mas também "estava pronto para enfrentar seus inquisidores (...), defender seu partido e suas causas". Da forma como Horowitz se lembra, o interrogatório permitiria que seu pai entrasse "no drama da história" e provasse sua lealdade.

Mas ele não fez isso. 0 partido decidiu que seria melhor se Horowitz se declarasse vítima de antissemitismo. Era uma evasiva humilhante, porque ele sempre se orgulhara de ter "deixado seu gueto judeu para trás". Mas a consciência de um homem não importava. "Quando chegou o momento", continua Horowitz, "meu pai seguiu a linha do partido como 


\section{retrato intelectual}

sempre fizera". Ele foi demitido por seu comunismo e não conseguiu nem mesmo sair com dignidade.

O Sr. Horowitz e a Sra. Colloms são as figuras trágicas no drama da esquerda americana desenhado por Horowitz. Ambos são crentes verdadeiros que ficaram sem ter para onde ir depois que suas crenças fracassaram. A fé que tinham era genuína e eles nunca renunciaram a ela. 0 que transcorreu foi o contrário: a crença tornou-se mais forte e desconectada da realidade mais imediata (as revelações de Khrushchev sobre Stalin, a repressão soviética na Hungria e em Praga e a resiliência do capitalismo nos EUA etc.), sem mencionar as solicitações de sacrifício pessoal que entravam em contradição com os ideais humanitários apregoados pelos socialistas. Sem escolha, sobrou o desânimo. Embora as mentiras que eles contaram e os danos que causaram tenham ocorrido há muito tempo, vale a pena recordar, pois as condições às quais se apegavam eram ilusórias, o que revela facilmente o sofrimento individual e a falência moral de uma ideologia que, muitas vezes apresentada como branda - porque nunca produziu assassinatos em massa na América -, não deixa de ser nociva.

Quando Horowitz começou a escrever contra a esquerda, nos anos de 1980,-Norman Podhoretz o aconselhou a mudar de assunto. Por que se preocupar com personagens marginais que não têm mais influência política?

Podhoretz talvez escolhesse Elaine Brown como um exemplo. Horowitz teve muito contato com ela em meados dos anos de 1970, quando ela presidiu os Panteras Negras - na ausência de Huey Newton, que tinha ido para Cuba depois de matar uma garota de programa em Oakland. Brown tinha um considerável poder local, chegou perto de ganhar uma eleição para o Conselho Municipal de Oakland, foi delegada do Partido Democrata, apoiou Jerry Brown na convenção do partido em 1976 e chegou a participar de uma conspiração com Tony Kline - ex-advogada dos Panteras Negras e do gabinete de Jerry Brown - para preencher os julgamentos vagos na Califórnia.

Havia rumores de que ela arrecadara um adiantamento de US $\$ 450$ mil para seu livro de memórias A Taste of Power: A Black Woman's Story. Depois, quando publicado, em 1992, escreve Horowitz no seu "Volume I", ela sai em turnê divulgando o livro na companhia de um dos "velhos capangas" de Huey, Flores Forbes, que havia cumprido quatro anos de prisão, acusado de assassinato em segundo grau. Horowitz também se lembra dela gritando ao telefone com um apresentador de TV local: "Eu vou matar você, seu filho da (...)". Todo o problema era que ele queria entrevistar Bobby Seale, que havia sido expulso do partido dos Panteras Negras alguns meses antes. Quando Horowitz perguntou a ela sobre Betty van Patter, uma mulher que os Panteras haviam contratado (por recomendação) como contadora antes de seu desaparecimento e assassinato, ela disse a ele: "Se você for atropelado por um carro ou algo assim, David, eu ficaria muito chateada, porque as pessoas diriam que fui eu que fiz isso".

Horowitz gastava energia e cita em seu livro "radicais abatidos" como Tom Hayden e 
outros tantos nomes menores; para o comentarista Norman Podhoretz, tratava-se de uma forma de Horowitz se justificar diante do fato de que muitas vezes ignorava adversários mais poderosos - como os liberais que não eram exatamente esquerdistas. Horowitz não cita nomes, mas podemos presumir que Podhoretz se referia a pessoas como Jimmy Carter e Garry Wills, ${ }^{7}$ que eram suaves na política externa e duros na política doméstica, como, por exemplo, com relação a Reagan. Eles detinham poder real na política e na cultura; Stokely Carmichael e Abbie Hoffman, não. Dois anos depois de sua conversa com Podhoretz, Huey Newton foi morto a tiros em uma calçada de Oakland por um traficante de drogas furioso.

É verdade, Horowitz admite, eles são marginais agora, mas as ideias e táticas da esquerda radical não desapareceram com esses intelectuais. As visões sublimes de igualdade e felicidade que são assumidas pelos conservadores, bem como pelos liberais, por trás das táticas de braço forte da esquerda se tornaram ortodoxia nas zonas cultural, intelectual e profissional da sociedade americana - e, é claro, no Partido Democrata. Na introdução de Ruling Ideas, Horowitz diz: "Quando comecei o projeto de descrever esse movimento, na década de 1980, o surgimento da esquerda como uma força dominante na vida política americana era relativamente recente e inadequadamente compreendido". Seu triunfo no século XXI foi demonstrado com perfeição por aquele que logo se tornaria presidente dos EUA, Barack Obama. Em 2008, Obama, em discurso, prometeu: “Transformar fundamentalmente os Estados Unidos da América" (o volume VII é intitulado A esquerda no poder: De Clinton a Obama). 0 presidente Obama não parecia nem soava como um radical dos anos 1960 - nenhum mau comportamento, uma vida familiar burguesa -, mas, uma vez presidente, ele prontamente politizou o fisco, e outras agências, inseriu a identidade de gênero em regulamentos nunca destinados a isso e ficou totalmente à vontade com os rappers na Casa Branca. Trata-se de uma acomodação liberal por parte da esquerda, sem abrir mão das mesmas crenças e objetivos de antes, mas com um toque mais leve uma vez no poder. Quando CEOs da América corporativa se juntaram à Casa Branca para promover iniciativas de diversidade e políticas voltadas, entre outros, para o público transgênero, o que Horowitz viu foi o reflexo das políticas de engenharia social tão radicais quando sempre foram. Está, assim, claro para Horowitz que a esquerda não morreu, como muitos acharam que tinha morrido, após a eleição de Reagan, em 1980, e em 9 de novembro de 1989, com a queda do Muro de Berlim.

\section{Não é a esquerda que tem problemas, é a direita que é patologicamente insana}

Manobras esquerdistas também se tornaram comuns. 0 julgamento que a amiga de infância de Horowitz dirigiu a ele na carta que ela escreveu depois da troca de insultos por telefone é um bom exemplo. Ela o rotula de psicologicamente perturbado, mas Horowitz

\footnotetext{
${ }^{7}$ Nota do tradutor: escritor, ganhador do prêmio Pulitzer. Wills escreve sobre religião, especialmente sobre a Igreja Católica, mas também sobre o islã. Cf. https://www.youtube.com/watch?v=ulK5re6b52g. Acessado em $11 / 11 / 2018$.
} 


\section{retrato intelectual}

sabe muito bem que não cabe a si a tarefa desesperada de provar sua inocência, ou seja, sua sanidade. Julgar um dissidente como mentalmente desequilibrado é um antigo método comunista. No volume VIII da série, The Left in the University, Horowitz observa que os acadêmicos haviam adotado esse artifício quando o tema era a historiografia da Guerra Fria. A versão de "consenso", nas palavras de um professor que Horowitz cita, começa com a premissa de que "um medo exagerado e irracional diante do comunismo... criou uma atmosfera de perseguição e histeria”. Às vezes, é difícil perceber quão drástica é essa tese radical da irracionalidade conservadora, talvez por seu longo legado, desde The Authoritarian Personality, de 1950, um influente estudo sociológico conduzido por Theodor Adorno que alinhava as inclinações fascistas com as crenças de direita, até, por exemplo, a contemporânea observação infame do presidente Obama sobre os brancos da classe trabalhadora: "Eles ficam amargos, se agarram a armas, religião ou antipatia a pessoas que não são como eles, alimentam sentimento anti-imigrantes ou pregam o isolacionismo comercial como forma de explicar suas frustrações".

Muitos colunistas e apresentadores liberais (de esquerda) agora tomam, como ponto de partida, o conservadorismo como patologia, e os conservadores do establishment não responderam de forma eficaz. Horowitz acredita que esse é outro exemplo em que a direita não conseguiu entender como a esquerda funciona. Na carta citada acima, temos alguém de esquerda oferecendo-se para entender o erro de um renegado examinando sua psique. Um ato que poderia ser tomado como um modo de simpatia ou, pelo menos, uma percepção mais ampla do que apenas sua política. Mas isso só repetiria um erro tolo da direita, o único, escreve Horowitz, pelo qual "os conservadores aceitaram de maneira imprudente as alegações enganosas da esquerda de serem 'liberais' e 'progressistas', atribuindo-lhes intenções idealistas". Aceitar a premissa psicológica faz com que os conservadores não percebam como a esquerda altera o debate.

Por muito tempo, os conservadores acusaram os esquerdistas de politizar tudo e todos, mas a premissa psicológica faz o oposto. Isso despolitiza o conservador e o conservadorismo. Quaisquer que sejam as opiniões políticas que ele detenha, acabamos por vê-lo como um ego frágil e iludido. 0 conservadorismo, portanto, não é mais uma perspectiva política que deve ser combatida por meios democráticos. É uma condição psicossocial, e isso não é algo que você debate. Em vez disso, você limita, confina aquele que está sofrendo, que sofre de um desvio ou de uma patologia psicossocial. 


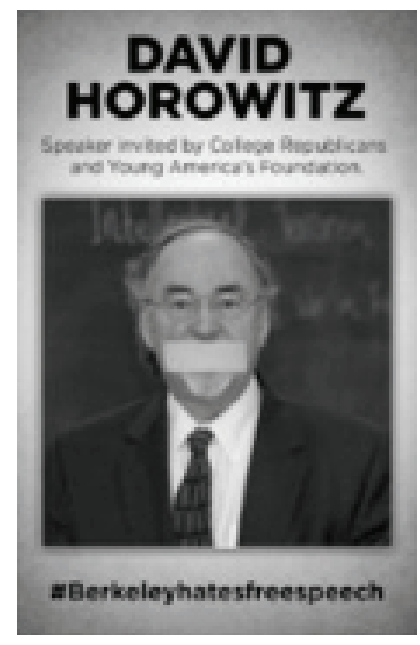

Cartaz de divulgação/ protesto na ocasião da tentativa fracassada de organizar uma palestra com David Horowitz em Berkeley em abril de 2017

Não é preciso muita arrogância para sustentar essa abordagem e esse diagnóstico quando uma comunidade estabelecida de liberais a reforça e a condescendência é seu modo padrão de lidar com os conservadores. Além disso, observa Horowitz, uma visão positiva e simpática de si acompanha essa leitura: "As pessoas que se identificam com a esquerda frequentemente fazem a seguinte pergunta: como é possível que seres humanos decentes não sejam progressistas como nós?". Se esse é seu julgamento primário das pessoas que se diferem de você politicamente, então você não pode reconhecer suas diferenças como políticas. Elas devem ser patológicas, ou seja, no limite, os conservadores são estúpidos ou venais. E o que você é? Compassivo e informado.

\section{A esquerda que é superficialmente radical}

Uma reflexão de 47 páginas sobre Christopher Hitchens é a última peça da escrita de Horowitz no presente volume e é a mais longa discussão sustentada de qualquer figura em todo o projeto. No começo, não está claro por que ele inclui isso. Eles se encontraram uma vez, em 1970, em Berkeley, mas não novamente até 1982, e Hitchens nunca fez parte da esquerda americana da qual Horowitz escapou ao longo daqueles anos. É verdade que Hitchens nunca abandonou sua admiração pelos antigos radicais, e seu ódio por todas as religiões também não mudou. Mas ele também renunciou ao antipatriotismo da esquerda após os ataques de 11 de Setembro e, muitas vezes, reconheceu a obsolescência do pensamento socialista no século XXI. Ele não se parece com as outras figuras desta história. Hitchens era, notoriamente, um "do contra", um homem de "contradições incontroláveis", observa Horowitz, que se opôs à Guerra do Vietnã, mas aprovou a invasão do Iraque, alguém que defende posturas "pró-vida" sem deixar de ser simpático ao feminismo dogmático. De fato, essa tendência independente, expressa com "charme trapaceiro e escrita vibrante", 


\section{retrato intelectual}

explica seu status no mundo intelectual desde a época em que ele se tornou o colunista mais popular da nação, nos anos de 1980, até sua morte por câncer de esôfago, em 2011.

Horowitz atribui sua eminente contrariedade a outra coisa, não à independência, mas a certo tipo de superficialidade. A ocasião para o perfil de Horowitz é a publicação do livro de memórias de Hitchens, Hitch-22 (2010), que ele elogia por sua perspicácia divertida e pelo estilo enfant terrible de sua persona. Mas, ele afirma, um fator crucial está faltando. Nesse relato de uma vida agitada e de lutas pessoais, escreve Horowitz, não obtemos uma verdadeira "curiosidade introspectiva essencial a tal tarefa ou a investigação interior que desdobraria seus mistérios tanto para si quanto para os outros". Hitchens cita a morte de sua mãe, que se matou em Atenas em um pacto de suicídio com o clérigo com quem fugiu, um "momento lacerante e uivante em minha vida". Isso acontecera quatro décadas antes, quando Hitchens tinha apenas 24 anos, e ele se lembra dela, à luz da sua infância, como uma mulher vibrante, cosmopolita, cheia de doçura. Mas a lembrança nunca se volta para dentro dele mesmo. Hitchens não explora como o suicídio dela o afetou. Em vez disso, ele faz um ensaio sobre a questão da autochacina, que, diz Horowitz, se lê como "um trabalho acadêmico sobre a psicologia e a sociologia do suicídio".

0 hábito de evitar a introspecção é recorrente. Hitchens menciona, por exemplo, "a experiência de se sentir preso à história", e esperamos ouvir o porquê disso ou como ele chegou a isso, mas "Christopher não faz nenhuma tentativa de fornecer respostas, nem parece provável que ele mesmo se fez as perguntas".

Horowitz contrasta essa relutância com suas próprias memórias. Em Radical Son, ele faz uma odisseia de autoconfrontação implacável que inclui retratos da vida, uma busca pelas ideias mais íntimas de seus pais e colegas revolucionários. Depois que Hitchens descobre que tem câncer e pensa em seus filhos vivendo sem o pai, há uma espécie de autocrítica. Mas ele não vai além de dizer: "Eu teria que dizer, para não ser um hipócrita, que minha vida é minha escrita antes de ser qualquer coisa. Porque é quem eu sou e meus filhos vêm depois; e isso eles tiveram que suportar".

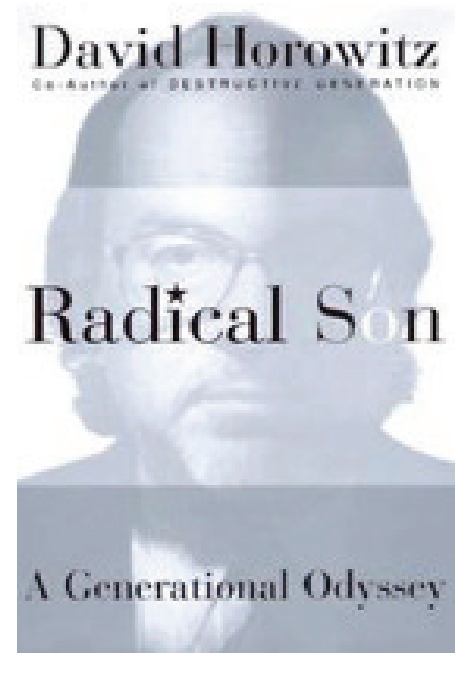

Ed. Touchstone, 1998 


\section{retrato intelectual}

Essa indisposição de olhar para dentro, "quem sou eu", de avaliar os motivos elementares e os erros específicos, é, na opinião de Horowitz, um traço característico do progressista exuberante. Hitchens fala longamente sobre si mesmo, mas não muito profundamente. Isso indica por que ele foi capaz de saltar de uma posição para outra, de forma inconsistente. $\mathrm{O}$ excesso de autoconsciência iria paralisá-lo. A introspecção retarda os julgamentos de um homem e os restringe a um caminho linear. Uma consistência tola é o duende das pequenas mentes! Ao não examinar a si mesmo, suas crenças e palavras ditas no passado, Hitchens poderia ocupar um meio-termo conflituoso, a meio passo entre ideais radicais que reconhecia serem equivocadas, mas sem submeter a elas e a si mesmo a uma análise e a um arrependimento completos. Os radicais não gostam de se examinar a não ser para se certificar de que permanecem fiéis à fé radical. Se o fizessem, não seriam mais radicais. Hitchens merece ser o perfil principal do Livro The Black Book of the American Left por essa mesma razão.

\section{Guerra sem fim}

Por muitos anos, David Horowitz foi considerado um outsider entre intelectuais, editores e jornalistas conservadores do establishment. Ele é muito contundente, combativo e de confronto, eles alardeavam. Dizia-se que ele tinha mudado de lado, mas não de estilo. Ainda era como em Berkeley, em 1966. Em 2003, quando ele iniciou sua campanha de Declaração de Direitos Acadêmicos (registrada no Volume VIII), os republicanos haviam ocupado a presidência de ambas as casas do Congresso e poderiam indicar três nomes para a Suprema Corte. Nesse contexto, por que instigar o ambiente universitário, onde os conservadores já eram desprezados? Ele publicou Hating Whitey and Other Progressive Causes em 1999 e entrou na guerra contra os movimentos reparatórios logo depois, ao inserir editoriais em jornais listando as razões pelas quais os afro-americanos tiveram a sorte de viver nos Estados Unidos, não na África. Esse era exatamente o tipo de controvérsia racial que os políticos republicanos queriam evitar. Horowitz não sabia que, ao falar em raça e em questões raciais, os conservadores sempre saíam perdendo?

Sim, Horowitz atingiu as pessoas como um raio em 2003 - incluindo as da direita como um autor cujas credenciais são o exagero e o drama. E, a esta altura, o grande público reconhecia que alguns esquerdistas selvagens podiam ser encontrados na academia, seja nos departamentos e em "grupos de estudos", seja em organizações como a Coalition to Defend Affirmative Action, Integration \& Immigrant Rights, and Fight for Equality by Any Means Necessary (BAMN) ${ }^{8}$ e o ACT UP, ${ }^{9}$ um grupo de defesa e militância pelas causas gays, ambas organizações famosas por manifestações barulhentas e com grande mobilização nos anos de 1990, mas, olhando pela perspectiva da cultura política daquele momento,

\footnotetext{
${ }^{8}$ Nota do tradutor: cf. http://www.bamn.com/. Acessado em 11/11/2018.

9 Nota do tradutor: cf. http://www.actupny.org/. Acessado em 11/11/2018.
} 


\section{retrato intelectual}

parecia que eles não teriam mais o impacto que já haviam tido. Era, afinal, um renascido cristão do Texas quem ocupava a Casa Branca!

Bastaram 15 anos para tudo mudar novamente. Voltamos a ouvir falar em "supremacia branca" como se ainda não tivéssemos aprovado a Lei dos Direitos Civis, e o Partido Democrata de hoje age como se nunca tivesse sido racista. As principais agências de notícias ecoam as alegações e denúncias de crime de ódio propagadas pelo esquerdista Southern Poverty Law Center (SPLC) ${ }^{10}$ e o novo status da SPLC e tal, como se fosse ele a consciência racial da nação. 0 prefeito da cidade de Nova Iorque quer bloquear a licença da rede de fast-food Chick-fil-A porque seu CEO defende uma concepção bíblica de casamento, e, no espetáculo mais popular da Broadway do nosso tempo, um ator sai do personagem para atacar o vice-presidente por suas "visões atrasadas". A América corporativa treme com medo de boicotes esquerdistas e sabe que todos ali terão sua narrativa de vítima.

E, se não bastasse a guerra cultural reaquecida, boa parte da população, estimulada pela mídia, pelo meio acadêmico e pelo mundo das artes e do entretenimento, com novo fôlego esquerdista, se recusa a aceitar os resultados da eleição. Obama - por eles considerado como "homem ideal" - deveria ser sucedido pela primeira mulher a presidir os EUA. A eleição de Donald Trump foi automaticamente lida com um retrocesso, a eleição de um "macho alfa" foi lida como um desastre. 0 dia 8 de novembro de 2016 foi considerado um trauma, e eles não conseguem superar isso até hoje. A dinâmica de conflito e resolução que a experiência democrática americana proporciona não lhe interessa. A 200 metros da rua da minha residência, um grande estandarte está pendurado nas janelas do segundo andar. Lê-se: "RESIST" em letras brancas sobre um fundo preto. Nada mais, apenas uma palavra.

O verão de 2018 faz o Horowitz de 20 ou 30 anos atrás parecer muito presciente. Ele alertou os conservadores, em termos alarmantes, do que estava por vir; ele lembrou aos esquerdistas seus erros embaraçosos; recusou-se a glorificar os bons e velhos tempos de agitação e, em vez disso, registrou o dano que causaram e continuam a causar; ele escolheu as questões mais sensíveis de raça, liberdade de expressão e o significado de uma nação como os EUA, dizendo aos conservadores que não poderiam fugir desses temas e desses debates. Irving Kristol anunciou em 2001 que os conservadores haviam perdido a guerra cultural (embora ele reservasse a religião como uma força e um campo em que a esquerda não havia vencido). Horowitz discorda de Kristol. Não que a esquerda não tenha conseguido vitórias após vitórias; ele discorda de que a esquerda ache que a guerra acabou. Isso nunca acaba, não para eles. Na mente progressista, Horowitz insiste, há sempre muito mais a fazer.

Conservadores dispostos a ceder e a aceitar a pauta progressista, acreditando que assim teremos paz social e que estarão contribuindo para pacificar a cultura política, estarão agindo como ingênuos. Essa é a lição de Horowitz. Enquanto a esquerda tiver influência

\footnotetext{
10 Nota do tradutor: cf. https://www.splcenter.org/. Acessado em 11/11/2018.
} 
na política americana, ficaremos presos em uma guerra cultural, quer queiramos, quer não. Ser um guerreiro cultural conservador é ver a esquerda não como um segmento de uma pólis americana pluralista, mas como uma quinta-coluna não liberal, não tão secreta, ansiosa para monopolizar a vida cívica e os assuntos privados. Para a esquerda, as eleições de 2016 foram um chamado para uma luta de "vida ou morte".

Quanto à trajetória intelectual de David Horowitz, o que chega até aqui é a denúncia da esquerda em todas as suas estratégias e modos de pensar e agir, feitas a partir de uma perspectiva aguerrida. Trata-se de um típico intelectual dos anos de 1960, ao estilo de um "guerreiro cultural", mas que definitivamente não quer ser meramente alarmista. São respostas sensatas a um adversário zeloso. 